\title{
Musicality in human evolution, archaeology and ethnography
}

\section{Iain Morley: The prehistory of music: human evolution, archaeology, and the origins of musicality. Oxford University Press, Oxford, 2013}

\section{Anton Killin}

Received: 19 February 2014/ Accepted: 21 February 2014/Published online: 7 March 2014

(C) Springer Science+Business Media Dordrecht 2014

\begin{abstract}
This essay reviews Iain Morley's The Prehistory of Music, an up-to-date and authoritative overview of recent research on evolution and cognition of musicality from an interdisciplinary viewpoint. Given the diversity of the project explored, integration of evidence from multiple fields is particularly pressing, required for any novel evolutionary account to be persuasive, and for the project's continued progress. Moreover, Morley convincingly demonstrates that there is much more to understanding musicality than is supposed by some theorists. I outline Morley's review of the archaeological and ethnographic literature, and then go on to critique his assessment of philosophical and evolutionary theories, offering some alternative perspectives that might better benefit his project.
\end{abstract}

Keywords Musicality - Evolution of music · Philosophy of music · Palaeoanthropology $\cdot$ Music archaeology $\cdot$ Ethnomusicology $\cdot$ Evolutionary aesthetics

\section{Prelude}

A prospering interdisciplinary research project has emerged over the last three decades comprising the work of a diverse array of theorists on evolution and cognition of music. This includes anthropologists, archaeologists, cognitive scientists, philosophers, musicologists, evolutionary biologists and psychologists, among others (see e.g. Bannan 2012; Wallin et al. 2000). Iain Morley's The Prehistory of Music is a comprehensive and sophisticated outline of the present state of play by a leading authority. Morley examines recent developments in several

\footnotetext{
A. Killin $(\bowtie)$

Department of Philosophy, Victoria University of Wellington, PO Box 600, Wellington,

New Zealand

e-mail: anton.killin@vuw.ac.nz
} 
scientific fields, and critically engages with research in philosophy and evolutionary theory. Although experts may gain little empirical insight concerning their own field, the charm of this book is in its interdisciplinary approach. Morley emphasises connections between areas of research and links theories with potential evidential support. The text is geared seamlessly to academics, students, and general readership; its accessible style and keen exposition will no doubt garner enthusiasm for the project.

First, what is music and musicality? On Morley's conception, very briefly, 'music' targets the cultural thing or set of cultural things of relevance; 'musicality' encompasses the biological aspects that enable the cultural thing(s) to be produced and appreciated (p. 5). ${ }^{1}$ This way of distinguishing music from musicality is not uncommon, though it is open to criticism. If the cultural and biological features of music/musicality co-evolved, attempts to artificially split them may be problematic.

As hinted above, Morley has a methodological message: understanding musicality is an interdisciplinary project. The book can also be seen as an attempt to refute the view that musicality is superfluous to understanding human nature. In other words, it is wrong to assume that music's cross-cultural ubiquity and value have little to do with our evolved biology and psychology. Much of this takes place through chapters 5-10, which comprise an extensive overview foregrounding the complexity of music's underlying capacities, dipping into palaeoanthropology, developmental psychology, musical cognition, neuroscience, and so on. Morley considers the evolution of hominin vocalisation and audition, relationships between music and language cognition, differences in musical cognition between trained musicians and other folk, innate versus learned musical capacities, links between vocalisation and gesture, entrainment to external pulse, whether the brain has a 'music module', and so on. Morley's commentary throughout is generally very sensible and I have little critical to say about these chapters here; the text is lucid, informative and I recommend it to any interested readers. The take home message is that several ingredients of our musicality may be very old; that perhaps the biological preconditions for compound vocalisation including singing, for instance, were in place by Homo ergaster (of course this is not to claim that singing or music is so old). ${ }^{2}$

However, nor is music relatively recent. I begin by summarising Morley's discussions of archaeology and ethnomusicology (chapters 2-4). Morley argues that musical traditions predate the emergence of known Upper Palaeolithic musical instruments; given the sophistication of the latter, rightly so. Morley looks to the musics of hunter-gatherer societies "to examine and illustrate a wider diversity of the musical behaviours that exist" (p. 12), to survey the nature and functions of their music, their instrumentation and materials. The music of Morley's target groups heavily relies on the voice, with mostly percussive instrumentation. This is not to give a crude 'ethnographic analogy', but rather to demonstrate a variety of ways of

\footnotetext{
${ }^{1}$ All page references throughout cite The Prehistory of Music except where noted.

${ }^{2}$ Other prerequisites for musicality such as dependency sensitivity and pattern recognition are far more ancient, over 36 mya (Ravignani et al. 2013).
} 
being musical with resources that might not fossilise or that require little modification.

I then turn to Morley's critique of philosophical and evolutionary hypotheses, respectively. In chapter 10, Morley considers the work of philosopher Stephen Davies, a defender of the 'contour theory' of music's expressiveness. Although Morley offers several criticisms of that view, I suspect that they miss their mark. Moreover, Morley's alternative is not clearly articulated. In any case, this particular focus strikes me as misplaced because Davies' argument is contextualised in aesthetics and the art music of the West, not music or musicality broadly considered. I briefly propose a different direction for theorising about musical emotional expression that may be more fruitful for Morley's project.

Finally, I review Morley's take on the origin and evolution of music/musicality debate (chapter 11). There is already an extensive evolutionary literature on musicality and its purported 'proper' functions. Morley does not subscribe to any novel theory of musicality's evolution, but rather extricates oft-conflated distinctions and evolutionary pressures, painting as clear a picture of the origins and evolution of music/musicality debate as there has been. Morley espouses a five-part framework of co-evolutionary pressures which supplants some standard yet simplistic theorising about music. Yet it may not be rich enough still: I tentatively suggest that taking a niche construction perspective explicitly might provide an upgrade to the framework. Moreover, it is not yet put into action; Morley has given us the blueprint for his model, but not yet used it to test scenarios for plausibility against evidence or to support a particular theory, hybrid or otherwise.

\section{Music archaeology}

Prehistoric musical instruments and sound-producers identified by Morley include bird-bone and ivory flutes, whistles (pierced reindeer-foreleg phalanges), purported bullroarers and rasps, and various forms of struck percussion (including strikemarked lithic and bone sources). Morley argues that the earliest known musical instruments (c. $40 \mathrm{kya}$ ) could not represent the earliest musical traditions, contra some theorists who have focused on the purported artsy and symbolic explosion of 'behavioural modernity' around that time. His analysis is accompanied by extensive inventories of prehistoric instruments, a useful adjunct resource.

To date there are 104 undisputed prehistoric flutes (p. 35)—direct evidence of Upper Palaeolithic musical activity. ${ }^{3}$ A number of flutes revealed in the Swabian Jura range in southwestern Germany (specifically, the caves Hohle Fels, Vogelherd and Geißenklösterle), are dated 36-40 kya (Higham et al. 2012). Most of the Swabian Jura flutes are modified bird-bone, predominantly vulture ulna and radius bones. Two swan-bone flutes were discovered in Geißenklösterle. ${ }^{4}$ Another find at

\footnotetext{
3 This is a conservative figure, discounting items whose anthropogenesis or status as intentional soundproducer is contested (such as the infamous Divje babe I 'Neanderthal flute', pp. 38-41).

${ }^{4}$ Such a small sample size suggests that they were brought there (p. 47).
} 
Isturitz, France constitutes a large sample of around twenty bird-bone flutes. Their ages vary from 32-35 to 11-17 kya (d'Errico et al. 2003).

One of the oldest known undisputed flutes is from Holhe Fels, made from a griffon vulture (Gyps fulvus) radius, $21.8 \mathrm{~cm}$ long, $0.8 \mathrm{~cm}$ diameter. The proximal end of the bone has been manually adjusted (a V-shaped hollow area has been carved) so as to better function as a mouthpiece. The body of the flute has been scraped smooth and fingerholes inserted "by thinning the surface of the bone, creating a cratered depression in which the finger can sit and make an airtight seal, and piercing a hole in the centre of this depression" (p. 42). Horizontal incisions near the flute's fingerholes suggest that measurements were made in order to position the holes (Conard et al. 2009). This may suggest that the flute was created with a pitch/scale standard in mind.

The Swabian Jura also revealed mammoth-ivory flute fragments, the oldest dated also from roughly $40 \mathrm{kya}$ (p. 50). Greater skill, precision work and effort is required to produce ivory flutes (let alone acquire the raw material), so it is no surprise that there are far fewer ivory than bird-bone flutes in the archaeological record. Vulture and swan radius and ulna are naturally hollow and an appropriate size; ivory is oversized, layered, and tougher to work. To produce a flute,

a section of ivory must be sawn to the correct length, it must then be sawn in half along its length, the core lamellae must be removed, and then the two halves of the flute must be refitted and bound together with a bonding substance which must create an airtight seal in order for the pipe to produce a sound. (p. 50)

Given the greater demands on working ivory into an item that is in many ways only equal to its bird-bone counterpart, Morley assumes that its use as a raw material was considered significant and valuable (p. 51). In any case it certainly bespeaks the sophistication and maturity of musical technologies at this time. Reconstruction experiments of Swabian Jura flutes exhibit a wide range of tones and establish them as "fully developed musical instruments and not just whistles or pipes" (Conard and Malina 2008, p. 14). Although the oldest known, they could not have been among the very first flutes given their sophistication and design. We can safely presume that the creators and performers of these Aurignacian flutes knew what they were doing - they were not mere neophytes. The upshot: it is not plausible that 40 kya marks a transition from no musical traditions to musical traditions.

So, then, why do a fair number of flutes suddenly appear only from 40 kya? Is it due to a contingency of resources available and preservation? Or did something more significant happen? Morley conjectures that the prevalence of vulture-bone flutes "betrays a 'special relationship" between carrion birds and ancient hunters (p. 87). Moreover, Mary Stiner and colleagues have argued that avian fauna became crucial subsistence resources in the Upper Palaeolithic (Stiner et al. 2000; see also Cassoli and Tagliacozzo 1997). Vultures are large birds, common in some environments, and not threatening to prehistoric hunters. They would have provided excellent resources besides bones for musical instruments. Their bones are long, hollow, sturdy and light, so they were especially suitable raw material for flutes, and 
the discovery of this fact may be responsible for the sudden emergence of flutes in the archaeological record. In other words, if we are seeing a 'revolution' here, it is probably in the resources used (pp. 97, 323). Note that flute materials are not restricted to bone and ivory-bamboo, cane and wooden flutes appear widely in the ethnographic record, crafted from easily worked materials that are unlikely to fossilise. Flutes made from these or similar materials very plausibly could have predated bird-bone and ivory flutes and indeed co-existed with them. ${ }^{5}$

Even if we discovered them, we may not recognise very early musical instruments as such. For instance, Kuhn and Stiner (1998) identify a modified ungulate bone, c. 32-35 kya, reminiscent of rasps in some traditional musical cultures, though its function as a musical artefact is speculative. (Morley argues that use-wear analysis, which has been hitherto neglected, might shed much welcome light on the presently murky status of purported rasps, bullroarers, and the like. This seems right.) Other ancient instruments may have been made from reeds, tree bark, animal skins or other ephemeral resources, as found in the ethnographic record. There are lots of ways to be musical with natural objects that require minimal modification-consider conch shells, bison horns, hollow logs, stalactites and stalagmites (still part of musical traditions in Indonesia for example), and clapsticks of various sizes, shapes and density of wood. Furthermore, the voice is our very own in-built, natural musical instrument, and is the main focus of much traditional music. Morley reviews the ethnographic record to substantiate these suspicions and demonstrate the variety of music cross-culturally.

\section{Music in hunter-gatherer society}

Morley focuses on music in foraging societies rather than world cultures broadly construed. The mobile hunter-gatherer subsistence strategies of his target Native American, African Pygmy, Australian Aborigine, and North American Arctic groups mean that their traditional practices are not the result of agricultural lifeways. These groups occupy diverse environmental and ecological niches and their lineages are temporally as well as geographically widely displaced.

The Blackfoot and Sioux tribes of the American Plains, to briefly summarise one of Morley's case studies, are nomadic antelope and bison hunters. Their music is monophonic song (i.e. a single melodic line) accompanied by the likes of drums, rattles, rasps and bullroarers. Music pervades their religious activities, social dancing, war dances and puberty rites (p. 17). Many songs utilise vocables rather than words. Music used in connection with symbolic activities is generally not symbolic or propositional, but rather contributes to the context emotionally (McAllester 1996). However, some songs are more symbolic: Blackfoot sun dances are thought to entreat health, wellbeing and affluence ('Sun says to sing', p. 18).

\footnotetext{
5 Some theorists have speculated that kelp (Ecklonia maxima), common in some African environments (Anderson et al. 1997), was used for much earlier musical instrument production (e.g. Epsi-Sanchis and Bannan 2012); for a video demonstrating the production and performance of such instruments, simple yet capable of extraordinary musical expression, see <http:/www.youtube.com/watch?v=AphqGZsWZxk> Accessed 19 Feb 2014.
} 
Others are iconic, for instance a 'bleating calf' song used in a characteristic Blackfoot hunting strategy (rounding up a herd at the top of a cliff face and forcing them over, leaving gravity to do the rest; Kehoe 1999). Blackfoot and Sioux instruments include rattles made from cocoons, gourds, turtle shells and deer hooves, split wooden sticks, cocoon leg- and ankle-bracelet rattles, wooden rasps, bullroarers, drums (stretched skin membrane over wooden frame), wooden and birdbone whistles, and elder-wood flutes. Very few are the kinds of artefacts likely to fossilise.

Of course, hunter-gatherer societies are not models for prehistoric Homo. The point is that, despite great variability in musical style, hunter-gatherer music is predominantly vocal, with body percussion and percussive instrumentation constructed from organic, ephemeral resources. Morley's case studies demonstrate musical traditions and practices that we would not expect to see preserved archaeologically. Both mother-infant lullaby and group-based music feature significantly. Group-based music is typically not performed by elite specialists for a passive audience (as per Western music), but is a communal affair. Only a little melodic instrumentation is evident (e.g. flutes), which represent only small slices of the musical traditions. Furthermore, these studies confirm that music need not always be 'symbolic', so there is no need to presume that it comes after symbolism and abstract thought-human characteristics thought by some theorists to have come online relatively recently, contemporaneously with 'behavioural modernity'/'the great leap forward'.

Our ancestors have long been competent artefact producers and users (McPherron et al. 2010). Complex javelin-like tools, for instance, appear from 400 kya (Thieme 1997). Yet many of the musical instruments described above require little modification, much less than the Upper Palaeolithic vulture radius and mammoth ivory flutes, appearing from (merely) 40 kya. Musical instruments, in other words, could be much older, representing a long tradition of resource modification that ultimately gave rise to the flutes preserved. How much older, however, remains to be argued.

Appealing to comparative ethnomusicology foregrounds an issue within music academia. Comparative studies of the world's musical traditions shed light on the wide cultural variation of music, as well as inter- and intra-cultural similarities and the prospects for discovering universals. Since the second half of the twentieth century, however, ethnomusicologists have tended to focus on musical analysis in terms of political, social, cultural, economic, or gender theories, poststructuralism and postmodernism, power relations, pedagogy, and theories of meaning. Morley's interests add weight to the call for a return to the comparative study of traditional musics (see e.g. Savage and Brown 2013; Trân Quang and Bannan 2012).

\section{Music, emotion and expressivity}

It is well known that music can induce emotional responses in listeners. Moreover, music can be interpreted as having properties such as human emotions (Watt and Ash 1998); yet music (qua sound-structure) is not sentient, so its purported capability to express emotions is puzzling-it's not like music itself is sad, proud, joyous, sentimental, melancholic, or whatever. 
The nature of music's emotional expressivity is one of the most widely debated topics in philosophy of music (see Kania 2012). Morley's assessment focuses primarily on Davies (2001). Davies distinguishes symbolic theory, expression theory, arousal theory, and his preferred view, contour theory. The first interprets music's expressiveness as operating by means of associative, conventional, or arbitrary symbolic signs within a system. Just as the English word "sadness" is a symbol for sadness - it represents sadness, is about sadness-the idea is that sad music similarly represents sadness, by association or convention. That is, the emotion is not really expressed in the music, but is interpreted as such, so the emotion should not literally be attributed to the music. (The word "sadness" is interpreted by English-speakers as representing sadness, but not as exemplifying the property sadness.)

The other three theories identify emotions as properties of the music. Expression theory maintains that the composer or performer expresses his or her own emotions through the act of composing or producing sound; that is, it is their emotions being communicated. Arousal theory focuses on the emotions evoked in listeners, maintaining that music's expressivity is in its ability to induce emotional responses in people under standard conditions. As they stand, these two theories are obviously inadequate. ${ }^{6}$ Davies' contour theory, however, "abandons the attempt to analyse music's expressiveness as depending on its connection to occurrent emotions" (Davies 2001, p. 34).

Davies maintains that music expresses emotions by manifesting qualities characteristic of human emotions "by virtue of resemblances between their own dynamic structures and behaviours or movements that, in humans, present emotion characteristics" (Davies 2001, p. 35). Accordingly, slow, soft, lethargic music with descending melodies might exemplify 'melancholic-soundingness' (by resembling melancholic attitudes or behaviours) and thus express melancholy. So music's expressiveness is understood as a response-dependent (Davies 2006 elucidates this) property of the music. In sum, according to this view, music is sad when it is disposed to elicit an attribution of sadness irrespective of whether sadness is aroused in listeners, and irrespective of whether the composer or performer is feeling sad, but rather via resembling how human emotion characteristics manifest. Compare with how weeping willows look sad-their downturned, whispery structure resembles the shape of a hunched-over, downcast person.

Morley levels several complaints against Davies' contour theory. First, he claims that contour theory is not sufficiently equipped to explain human emotional responses to music. Indeed, but that is not its aim: it is an attempt to clarify the nature of music's expressivity (that is, how it is that music can express emotional content), which is not the same thing as, for example, why or how music

\footnotetext{
${ }^{6}$ Contra expression theory, composers/performers might not experience the emotion that the music is said to be expressing. That is, some music may seem (say) sad independent of whatever the composer or performer feels. Contra arousal theory, sometimes circumstances can engender sad emotional responses in audience members of happy, lively music, for instance. Furthermore, for a listener to correctly respond to music's expressivity (under standard conditions), she must recognise the emotion expressed by the music, which on pain of circularity cannot depend on her own emotional arousal. She can identify the music as sad without it actually making her sad.
} 
psychologically (or otherwise) influences human emotional affect. Therein may lay the cause of some confusion, if the explanandum of their arguments is different.

Second, Morley notes that our emotional responses to music utilise the same apparatus as our emotional responses to human vocalisations, posture and so on. Yet this strikes me as compatible with Davies' theory. Morley claims that listeners interpret music's emotional content "in the same way as physiological and corresponding auditory expressions of emotional state" (p. 265). However, that emotional responses to music are cognised in the same manner as emotional responses to vocalisations, posture, gait, and facial expressions betrays a causal role-it is not clear that it speaks to analyses of music's emotional expressivity.

Third, Morley protests that Davies unduly "separates physical and vocal expression of emotion" (p. 263). Davies does suggest that music's expressivity is more like the dynamic patterns "apparent in non-verbal, behavioural expressions of emotion" (Davies 2001, p. 35), though this is not to deny cross-modal cognising of emotive cues. Moreover, though Davies is sceptical of similarities between the expressivity of music and non-musical vocalisation in terms of inflection and timbre, he contends that "the voice and music are more alike in dynamic structure, articulation, pitch, intensity, and periodicity of phrase lengths and shapes" (Davies 2006, p. 181), so there is still plenty of scope for important resemblances between vocalisation and music (and not a necessary separation of them in the theory, as Morley supposes).

Morley does not clearly articulate an alternative theory of music's expressivity, so crucial differences between his and Davies' views do not come through strongly. ${ }^{7}$ One way to characterise the apparent dispute might be to compare Morley's view with simulation theory from philosophy of psychology and mind. Very briefly, according to simulation theory, people understand each other in part because they share the same mechanisms of perception, cognition and response. Morley may be offering a simulation theory-like account of human emotional response to music: humans are good at understanding music's emotional content because doing so utilises the same mechanisms as understanding emotional content in other domains-vocalisation, posture, and so on. Simulation theory contrasts with theory-theory, according to which people understand each other because they have and can apply a workable, deductive theory of how people think; a musical analogy might be similar to symbolic theory, suggesting that people are good at understanding music's emotional content by having and applying certain conventions and associations and deducing which emotion is said to be expressed. Davies' contour theory may well be compatible with the simulation theory analogy. At least, Morley does not say enough to call that assumption into question. I doubt his criticisms of the contour theory will persuade anyone who subscribes to that view. ${ }^{8}$

\footnotetext{
7 Indeed, Morley later claims that "The contours of musical stimuli can have much in common with physical (including vocal) expression of emotional state, stimulating the interpretation of emotion across the other media of expression that would normally be associated physically with that contour" (p. 315), which seems to be entirely compatible with Davies' view.

8 This is not to say that the view is without its dissenters; see e.g. Levinson (1996, 2006). For overview, see Kania (2012).
} 
More crucially: the debate over music's expressivity is contextualised within Western art music, specifically instrumental, non-programmatic and non-representational 'pure' music (Davies 2001, 2006; Kania 2012). Yet Morley is only peripherally interested in this very recent development in music's history. In other words, 'pure' music is an outlier, to which aesthetic theory applies, but is not particularly helpful in determining the connection between music broadly construed and emotion. So it is puzzling that Morley does not explicitly eschew such a focus in place of one that examines music's expressivity within the kinds of musics he identifies in the hunter-gatherer ethnographic record. ${ }^{9}$ The expression and arousal theories, dismissible as hopelessly simplistic in the context of Western art and aesthetic theory, may be salvageable for traditional musics. These musics, after all, should be Morley's test cases for expressivity, not the art music of the West. ${ }^{10}$ It could be argued that 'pure' art music today co-opts our disposition to express emotion via and/or be emotionally aroused by non-pure, non-art music (e.g. vocaldominant, ritual-, game- or hunting-associated traditional music, and so on). A significant role of that music boils down to intentionally communicated affect: consider mother-infant lullaby, a ubiquitous musical form. So the idea is a kind of tentative hybrid expression-arousal theory. Ultimately, however, this picture is compatible with contour theory for our outlying 'pure' music, which is abstracted from this context.

The relevance of human psychological and emotional responses to music is obviously important for Morley's evolutionary thinking, but as it stands, it is far from clear how the nature of music's expressivity integrates into his overall project. This section of The Prehistory of Music stands out as a somewhat underdeveloped foray into aesthetic theorising.

\section{Origins and evolution of music/musicality}

Does music have a proper function? What are its origins, and what explains its persistence? Dissanayake (2000) and Trehub (2003) emphasise mother-infant vocalisations; Dissanayake (1982) suggests that the arts imbue specialness which enhances ritual, improving group cohesion. Hagan and Bryant (2003) argue that music signals group cohesion. Livingstone and Thompson (2009) suggest that music emerged from theory of mind. Miller (2000) argues that music evolved via sexual selection. Cross (2007) proposes that music enabled domain-general cognition by integrating domain-specific mechanisms. Pinker (1997) argues that music is a mere 'pleasure' technology, and Patel (2010) argues that music is a useful 'transformative' technology. And there are many more hypotheses besides. Morley finds no single theory wholly convincing as an explanation for music. Instead, Morley

\footnotetext{
9 Towards the end of the discussion, Morley reminds us that traditional music is predominately vocal and such (p. 265), but leaves the thought underdeveloped.

${ }^{10}$ For a broader overview of emotion and communication in traditional vocal musics, including a useful taxonomic system, see Trân Quang and Bannan (2012).
} 
provides a clear picture of the origins and evolution of music debate and discusses prospects for its advancement.

These theories are often divided into 'adaptation', 'by-product' and 'cultural invention' camps (e.g. Davies 2012). Dynamic gene-culture co-evolution, a phenomenon we should take seriously in discussions of music's evolution, calls into question the usefulness of this overly simplistic set of distinctions (Killin 2013). It also undermines the music/musicality distinction, which might be better conceptualised as axes of a more holistic system, over time comprising interconnected levels of phenomena (cultural and biological), amenable to feedback loops, with bases in biology and its scaffolding cultural strata. So cultural evolution and (as I shall suggest) niche construction should play a more prominent role in explaining music.

Rather than rounding theories up into the standard categories, Morley espouses a framework comprising five selective pressures against which theories of music/ musicality's origin or evolution can be evaluated and categorised, distinguishing processes that have been conflated or ignored in some evolutionary hypotheses of music. Co-evolutionary feedback is possible within his framework and none of the pressures are necessarily mutually exclusive. Here I quote in full:

1. Selection for capacities underlying musical behaviours because of their value in other circumstances. Musical practice then gains its efficacy (effects and wider emotional and social benefits) from its use of these capacities. This efficacy then may or may not itself have selective benefits, but this would be a separate process;

2. Selection for the capacities that support musical behaviours, through their use in music, because of benefits of exercising those capacities together for other aspects of life (e.g. the action of participating in musical activities itself indirectly facilitates individual survival and procreation);

3. Selection for the capacities that support musical behaviours in the context of their efficacy in their use in music-i.e. benefitting the practice of music itself, which is itself selectively advantageous for some reason (i.e. the action of participating in musical activities itself directly facilities individual survival and procreation);

4. Sexual selection for musical capacities via musical practices because of the practices indicating fitness of participants due to potential survival benefits of the capacities that support them;

5. Cultural selection for particular musical practices (including capabilities to participate in those practices), which then may or may not have a biological effect via gene-culture co-evolution, through social functions of musical practice having knock-on effects on individual survival and reproductive rate. (pp. 276-277)

Preceding chapters in the book tended to deal with process 1; that is, with underlying biological capacities that musical practices rely on, but not necessarily selected for. However, hypotheses from the evolution of music literature sync up to different processes and combinations of processes. Morley links these theories to their respective place(s) in his framework. This demonstrates just how 
multi-faceted the evolution of music/musicality could have been, as competing theories that target different aspects of musicality could be compatible. ${ }^{11}$

So Morley supposes that multiple factors could have played a role in music's genesis, evolution and persistence; fair enough. Where relevant, he connects aspects of theories with potential evidential support from elsewhere in the book. What's more, he distinguishes theories of music's origins from theories of music's persistence and development, and rightly so. Group selection theories and sexual selection theories are more credible when considered as possible causes of the persistence of music, rather than as explanations for music's genesis, for instance. In prehistoric societies with musical traditions, musical skill could have 'honestly signalled' desirable traits in enough cases to make it advantageous, for example. (It probably still does.) Of course, this may not help us determine music's origins, or what's truly driving its evolution.

Acknowledging the possibility of dynamic biology-culture interaction and separating conflated selection processes and notions of origins and persistence in evolutionary hypotheses sheds light on prospective theories. But the picture could be complemented further-there is at least one more process that Morley's framework neglects. Humans are not only the products of their environments (ecological, cultural, etc.) but they influence and shape them too. Niche construction theory (e.g. Laland and O'Brien 2011; Odling-Smee and Laland 2011) gives a far richer perspective than standard evolutionary theory especially regarding aspects of human culture (e.g. architecture, see Odling-Smee and Turner 2011; tools, see Collard et al. 2011), and it warrants a place in the model.

Admittedly, Morley extends a quick tip o' the hat to Laland and colleagues (p. 290) and notes that the hunter-gatherer groups discussed above "use music to try to influence the world around them" (p. 309). Recall the Blackfoot 'bleating calf' song used in hunting; this strategy has ecological upshots. Yet humans also play a role in shaping their cultures, culture-specific exposure to music in turn influences musical cognitive development, and resultant musicality further shapes and feeds back. I doubt Morley would disagree with this assessment; yet an explicit exploration of the prospects of a niche construction perspective is an underexplored avenue for understanding music evolution. Taking such a perspective and explicitly integrating it into the kind of framework already espoused by Morley strikes me as a potentially fruitful upgrade to theorising about musicality, and Morley's framework is an attempt to do just that.

Finally, Morley offers a human-evolution timeline synthesising the empirical evidence from preceding chapters and sketching both anatomic and cognitive advances in the context of musicality. Given the interdisciplinary nature of the project, the integration of various evidence-streams here is both welcome and important. But what of the driving force behind music/musicality's evolution, and its relation to the five pressures identified above? Why did musicality evolve? And

\footnotetext{
11 Theories that fall outside of the scope of the framework-for instance the view attributed to Repp (1991) that music is a reasonably recent cultural product with no evolutionary consequence-are rejected since evidence discussed (e.g. development psychology, etc.) seems to contradict the idea that there are no innate biases for musical perception (pp. 278-279). Besides, Morley has given good reason to suppose that music predates the Upper Palaeolithic-long enough for genetic evolution to take place.
} 
when did music appear? The task that remains is "to clearly model the range of ecologically based scenarios in which such mechanisms might have operated, and to then test their likelihood against the available evidence" (pp. 318-319) —a job evidently left for another occasion.

Acknowledgments Thanks to Kim Sterelny and Stuart Brock for comments on earlier versions of the manuscript. I have also benefited from discussions on related themes with Kim Shaw-Williams and Adrian Currie.

\section{References}

Anderson RJ, Carrick P, Levitt GJ, Share A (1997) Holdfasts of adult kelp Ecklonia maxima provide refuges from grazing for recruitment of juvenile kelps. Mar Ecol Prog Ser 159:265-273

Bannan N (ed) (2012) Music, language, and human evolution. Oxford University Press, Oxford

Cassoli P, Tagliacozzo A (1997) Butchering and cooking of birds in the Palaeolithic site of Grotta Romanelli (Italy). Int J Osteoarchaeol 7:303-320

Collard M, Buchanan B, Ruttle A, O’Brien MJ (2011) Niche construction and the toolkits of huntergatherers and food producers. Biol Theory 6(3):251-259

Conard N, Malina M (2008) New evidence for the origins of music from the caves of the Swabian Jura. In: Both AA, Eichmann R, Hickmann E, Koch L-Ch (eds) Orient-archäologie band 22: Studien zur Musikarchäologie VI, vol 22. Verlag Marie Leidorf GmbH, Rahden, pp 13-22

Conard N, Malina M, Münzel SC (2009) New flutes document the earliest musical tradition in southwestern Germany. Nature 460:737-740

Cross I (2007) Music and cognitive evolution. In: Barret L, Dunbar R (eds) Handbook of evolutionary psychology. Oxford University Press, Oxford

d'Errico F, Henshilwood C, Lawson G, Vanhaeren M, Tillier A-M, Soressi M, Bresson F, Maureille B, Nowell A, Lakarra J, Backwell L, Julien M (2003) Archaeological evidence for the emergence of language, symbolism, and music_-an interdisciplinary perspective. J World Prehist 17(1):1-70

Davies S (2001) Philosophical perspectives on music's expressiveness. In: Juslin P, Sloboda J (eds) Music and emotion: theory and research. Oxford University Press, Oxford, pp 23-44

Davies S (2006) Artistic expression and the hard case of pure music. In: Kieran M (ed) Contemporary debates in aesthetics and the philosophy of art. Blackwell, Malden, pp 179-191

Davies S (2012) The artful species: aesthetics, art, and evolution. Oxford University Press, Oxford

Dissanayake E (1982) Aesthetic experience and human evolution. J Aesthetics Art Crit 41(2):145-155

Dissanayake E (2000) Antecedents of the temporal arts in early mother-infant interaction. In: Wallin N, Merker B, Brown S (eds) The origins of music. MIT Press, Cambridge, pp 389-410

Epsi-Sanchis P, Bannan N (2012) Found objects in the musical practices of hunter-gatherers: implications for the evolution of instrumental music. In: Bannan N (ed) Music, language, and human evolution. Oxford University Press, Oxford, pp 173-198

Hagan E, Bryant G (2003) Music and dance as a coalitional signalling system. Hum Nat 14:21-51

Higham T, Basell L, Jacobi R, Wood R, Bronk Ramsey C, Conard N (2012) Testing models for the beginnings of the Aurignacian and the advent of figurative art and music: the radiocarbon chronology of Geißenklösterle. J Hum Evol 62:664-676

Kania A (2012) The philosophy of music. In: Zalta E (ed) Stanford encyclopedia of philosophy (Fall 2012 edition). http://plato.stanford.edu/archives/fall2012/entries/music/. Accessed 23 Jan 2014

Kehoe A (1999) Blackfoot and other hunters of the North American Plains. In: Lee R, Daly R (eds) The Cambridge encyclopedia of hunters and gatherers. Cambridge University Press, Cambridge, pp 36-40

Killin A (2013) The arts and human nature: evolutionary aesthetics and the evolutionary status of art behaviours. Biol Philos 28(4):703-718

Kuhn S, Stiner M (1998) The earliest Aurignacian of Riparo Mochi (Liguria, Italy). Curr Anthropol 39 (3 suppl):175-189

Laland KN, O’Brien MJ (2011) Cultural niche construction: an introduction. Biol Theory 6(3):191-202

Levinson J (1996) The pleasures of aesthetics. Cornell University Press, Ithaca, NY, pp 90-125 
Levinson J (2006) Musical expressiveness as hearability-as-expression. In: Kieran M (ed) Contemporary debates in aesthetics and the philosophy of art. Blackwell, Malden, pp 192-206

Livingstone SR, Thompson WF (2009) The emergence of music from the theory of mind. Music Sci 13 ( 2 suppl):83-115

McAllester D (1996) North America/Native America. In: Titon J (ed) Worlds of music: an introduction to the music of the world's people. Schirmer, New York, pp 33-82

McPherron SP, Alemseged Z, Marean CW, Wynn JG, Reed D et al (2010) Evidence for stone-toolassisted consumption of animal tissues before 3.39 million years ago at Dikika, Ethiopia. Nature 466:857-860

Miller G (2000) Evolution of human music through sexual selection. In: Wallin N, Merker B, Brown S (eds) The origins of music. MIT Press, Cambridge, pp 329-360

Odling-Smee J, Laland KN (2011) Ecological inheritance and cultural inheritance: what are they and how do they differ? Biol Theory 6(3):220-230

Odling-Smee J, Turner JS (2011) Niche construction theory and human architecture. Biol Theory 6(3):283-289

Patel A (2010) Music, biological evolution, and the brain. In: Bailar M, Field C, Henry CJ (eds) Emerging disciplines. Rice University Press, Houston, pp 91-144

Pinker S (1997) How the mind works. Allen Lane, London

Ravignani A, Sonnweber R-S, Stobbe N, Fitch WT (2013) Action at a distance: dependency sensitivity in a New World primate. Biol Lett 9(6):20130852

Repp B (1991) Some cognitive and perceptual aspects of speech and music. In: Sundberg J, Nord L, Carlson R (eds) Music, language, speech and brain. MacMillan Press, Basingstoke, pp 257-268

Savage PE, Brown S (2013) Toward a new comparative musicology. Anal Approaches World Music 2(2):148-197

Stiner M, Munro N, Surovell T (2000) The tortoise and the hare: small-game use, the broad-spectrum revolution, and paleolithic demography. Curr Anthropol 41(1):39-73

Thieme H (1997) Lower Palaeolithic hunting spears from Germany. Nature 385:807-810

Trân Quang H, Bannan N (2012) Vocal traditions of the world: towards an evolutionary account of voice production in music. In: Bannan N (ed) Music, language, and human evolution. Oxford University Press, Oxford, pp 142-172

Trehub S (2003) The developmental origins of musicality. Nature Neurosci 6(7):669-673

Wallin N, Merker B, Brown S (eds) (2000) The origins of music. MIT Press, Cambridge

Watt R, Ash R (1998) A psychological investigation of meaning in music. Music Sci 2:33-54 